\title{
ÓLEO ESSENCIAL DE TAGETES MINUTA L. (Compositae) ESPONTĀNEA NO RIO GRANDE DO SUL *
}

N.C.S. Siqueira; L. Bauer; G.A.A.B. Silva; B.M.S. Sant'Ana;C.B. Alice e C.T.M. Bacha.

Departamento de Produção de Matéria Prima. Faculdade de Farmácia. UFRGS. Porto Alegre, RS.

RESUMO

Na relação dos componentes do öleo essencial de Tagetes mí nuta L. aparecem com maior percentagem a tagetona e o limoneno, en quanto estão entre os constituintes menores o p-cimeno e o $\alpha$-pineno. SUMMARY

SIQUEIRA,N.C.S.; BAUER, L.; SILVA,G.A.A.B.; SANT'ANA,B.M.S.; ALICE, C.B. and BACHA,C.T.M., 1982. Essential oil from Tagetes minutal. (Compositae), spontaneous in Rio Grande do Sul. Ciência e Natura (4):91-93.

Tagetone, limonene, $p$-cimene and $\alpha$-pinene have been iden tified from aerial parts of the whole flowering plants of Tagetes mi nuta growing in Rio Grande do Sul.

\section{INTRODUÇÃO}

A essência de Tagetes minuta L. ( Tagetes glandulifera Schrak), vulgarmente conhecido por Chinchila ou Cravo de Defunto, tem sido estudada na Austrālia e na Argentina. A composição quĩmica dos óleos voláteis destas procedências, mostrou a presença de d-lí moneno, ocimeno, dimetiloctenona e tagetona, com rendimento de $0,50 \%$ segundo Jones et alzi. (8) e 0,25 a 0,30\% de acordo com Fester et alzi. (5) Handa et alli. (6) encontraram 1\% de 01 leo essencial cons tituído de aromadendreno, tagetona, ālcool feniletīlico, ocimeno e aldeído salicílico. O vegetal Tagetes minuta, segundo Atkinson (1) (2) e (3), é fonte natural de tiofenos. De Villiers et alli. (4)sin tetizaram tagetenonas e estudaram a sua ocorrência em Tagetes minuta. Quantc ao seu aproveitamento terapêutico, Ickes et azzi. (7) verifi caram a atividade anti-tumoral de plantas floridas, colhidas ao aca so, com ação específica contra carcinona de pulmão "in vivo".

Maradufu et azzi. (9), isolaram por destilação das flores frescas e folhas, um larvicida de mosquito, o (5E) - ocimenone, com $100 \%$ de ação efetiva em 24 horas, contra larva de Aedes aegypty.

*Com auxîlio do CNPq. 
MATERIAL E METODOS

As amostras constituiram-se de sumidades floridas do vege tal Tagetes minuta L. coletadas no bairro Bela Vista, em Porto Ale gre. A extração foi processada em aparelho de Clevenger modificado (10), obtendo-se o rendimento de $0,4 \%$. 0 óleo essencial, apōs desse cação por sulfato de sōdio anidro, foi submetido à cromatografia em fase gasosa em cromatógrafo Shimadau $4 A P T$, com detetor de conduti vidade térmica, coluna de $3 \mathrm{~m}$ de comprimento e $0,3 \mathrm{~cm}$ de diāmetro in terno, fase estacionāria e suporte $\operatorname{SAIB/CGH}(20: 80), \mathrm{g}^{-}$as de arraste Hēlio com fluxo de $75 \mathrm{ml} / \mathrm{min}$, injetando-se 341 . A temperatura do de tetor foi $240^{\circ} \mathrm{C}$, da coluna e injetor $180^{\circ} \mathrm{C}$, corrente de $80 \mathrm{~mA}$ comate nuação de $8 \mathrm{mV}$ e a velocidade do papel de $10 \mathrm{~mm} / \mathrm{min}$.

RESULTADOS

0 óleo essencial apresentou rendimento de $0,4 \%$. Por anāl $\underline{i}$ se cromatogrāfica gasosa, foram determinados 4 constituintes corres pondentes aos picos registrados. Pico no $1, \alpha$-pineno com $2,4 \%$; pico nọ 2, 1 imoneno com 35,8\%; pico nọ 3, p-cimeno com 14,3 e pico no 4, tegetona com $47,3 \%$.

\section{DISCUSSAOO}

0 óleo essencial de Tagetes minuta apresenta um teor variā vel entre 0,2 e $1 \%$ de acōrdo com sua procedēncia. E provāvel que as condições climáticas interfiram neste detalhe, pois, os dados refe rem-se sempre a plantas em floração. Deve-se considerar tambēmagran de diversificação registrada para a sua composição quîmica, tendo-se verificado no Tagetes minuta do Rio Grande do Sul apenas 4 componen tes, com predomināncia de tagetona.

\section{CONCLUSAOO}

0 rendimento do óleo essencial das sumidades floridas de Tagetes minuta, vegetal espontāneo no Rio Grande do Sul, é interme diārio entre os constatados para as plantas da Austrālia ou Argentí na. Entretanto, ao ser considerada a sua composição química, verifi ca-se diferença entre os componentes encontradas em vegetais d'outra origem geográfica, tendo sido constatada a presença de tagetona em todos os exemplares estudados, sendo expressiva a sua percentagem (47,3\%) na espécie nativa do Rio Grande do Sul, que se faz acompa nhar de limoneno $(35,8 \%)$, de $p$-cimeno $(14,3 \%)$ e de $\alpha$-pineno $(2,4 \%)$.

\section{BIBLIOGRAFI A CITADA}

1. ATKINSON,R.E. et aZZi. Bithienyl derivatives from Tagetes minuta. Tetrahedron Letters, 43-44, p.3159-62, 1964. 
2. Naturally occurring thiophenes. Bitthienyl derivatives from Tagetes minuta. J.Chem.Soc. (Dec). p.7109-15, 1965 .

3 . Naturally occurring thiophenes. II. 5- (4 -chloro-3-hydroxy-but-1-yny1)-2-2-bithyenyl from T.minuta. J. Chem.Soc., C.org.(12) p.1101-3, 1966.

4. De Villiers,D.J.J. et alzi. Synthesis of tagetenones and their occurrence in oil of Tagetes minuta. Phytochemistry. 10(6), p. $1359-61,1971$.

5. Fester,G. et alli. Estudo sobre esencias volatiles argentinas. Revista de la Facultad de Ingenieria Quimica, p.31.32. 1961.

6. Handa,K.L. et alli. Perfumery Essential Oil Record, 54 p.372, 1963.

7. Ickes,G.R. et azzi. Antitumor activity and preliminary phitoche mical examination of Tagetes minuta (Compositae) J. Pharm.,62 (6), p.1009-11, 1973 .

8. Jones,J.H. et aZZi. Journ.Chem.Soc. 127, p.2530, 1925.

9. Maradufu,A. et alZi. Isolation of (5E)-ocimenone, a mosquito la vicide from Tagetes minuta L. Lloydia, 41(2), p.181-3, 1978.

10. Van 0s,F.H.L. Pharm. Weekblad 100, p.387, 1965.

Recebido em novembro, 1982; aceito em dezembro, 1982. 
